\title{
Relationship of Work Context and Work Stress among Sonographers in Riyadh, KSA
}

\author{
Uzma Zaidi 1 1,* Lena F. Hammad ${ }^{2,}$ Salwa S. Awad ${ }^{3,}$ Safaa M. A. Elkholi ${ }^{3,}$ and Hind D. Qasem ${ }^{1}$ \\ 1 College of Health and Rehabilitation Sciences, Department of Health Sciences, Princess Nourah bint \\ Abdulrahman University, Airport Rd, Riyadh 13416, Saudi Arabia; uazaidi@pnu.edu.sa (UZ); \\ hoqasem@pnu.edu.sa (HDQ) \\ 2 College of Applied Medical Sciences, Department of Radiological Sciences, King Saud University, Riyadh, \\ Saudi Arabia; lhammad@ksu.edu.sa \\ ${ }^{3}$ College of Health and Rehabilitation Sciences, Department of Rehabilitation Sciences, Princess Nourah bint \\ Abdulrahman University, Airport Rd, Riyadh 13416, Riyadh, Saudi Arabia; sasahmed@pnu.edu.sa (SSA); \\ smelkholi@pnu.edu.sa (SMAE) \\ * Correspondence: uazaidi@pnu.edu.sa; Tel.: +966-1182-40636
}

Academic Editor: Uzma Zaidi

Received: date; Accepted: date; Published: date

\begin{abstract}
Work context is essential to understand in relation to handle the stress at work that ultimately creates a feeling of satisfaction or dissatisfaction among health professionals. The current study was conducted to investigate the relationship of work context and work stress among sonographers $(\mathrm{n}=153)$ in Riyadh, Saudi Arabia. Additionally, the study provided a gender-based comparison of both variables among sonographers. Work context was measured by administering subscale of work context derived from Work Design Questionnaire. Whereas, work stress was measured by Job Stress Scale. In addition, relationship of lifestyle was explored with work context and work stress. Data was collected through survey research forms. Results revealed the significant relationship of work context and work stress ( $\mathrm{r}=.251, \mathrm{p}=.002)$. Among lifestyle variables, perceived good health $(\mathrm{r}=.214, \mathrm{p}=.008)$ and sleep $(\mathrm{r}=.242 . \mathrm{p}=.003)$ were found positively related with satisfaction toward work. Whereas, the strong positive correlation was found between work context and frequency of physical activity $(\mathrm{r}=.255, \mathrm{p}=.005)$. No significant difference was found among male and female sonographers. The findings of this study contributed to evaluating the working condition of sonographers in relation to work stress. Effective strategies for better working settings as well as strategies for achieving satisfaction in work will be discussed to enhance the performance of sonographers.
\end{abstract}

Keywords: work context; work conditions; work stress; job satisfaction; lifestyle; sonographers; ergonomics

\section{Introduction}

Healthcare professionals are exposed to the risk of work stress due to many reasons, that can affect their mental health status [1]. Several studies have explored various kinds of mental health aspects that formed by the work design and work structure [2]. Working context can enhance and impair mental health simultaneously [3,23,4]. Some studies investigated the effects of 'work-life balance', have proved the existence of interactions among waged work, family, public and social life [5]. Health professionals particularly, sonographers if not having excellent work context can suffer from several health issues, for example, musculoskeletal injuries (MSI) [6]. The literature revealed that health professionals face an elevated level of stress which leads to low self-esteem, low mood, somatic complaints, sleep disturbances, and burnout [7]. This high level of stress of health professional's grounds for both individual and organizational problems. Moreover, it can negatively affect the standards of the expected health care services. 
Work stress is one of the elements that negatively affect the performance of healthcare providers. It is caused by many reasons; sometimes it is related to personal characteristics, habits, lifestyle, personal incompetence and perceptual predispositions. Sometimes it arises from external sources, for instance, social interactions at the workplace which are specifically the work relationships and interactive contacts which have a significant effect on the quality of life at the workplace [8]. Sometimes work context including ergonomics, equipment used, working conditions provoke stress $[9,10]$. Health care professionals cannot provide the best of their potentials if the level of stress is high due to either reason $[10,11]$.

Sonographers as professional health care providers have reported a high prevalence of workrelated musculoskeletal pain and discomfort $[12,13]$. Some latest studies indicated the high prevalence of neck and shoulder pain among female sonographers $[14,15]$. Other researchers also studied the stress-related risk factors such as disproportionate workload, time pressure, tough or difficult tasks, insufficient rest breaks, monotony in conducting the same tasks, and the physically poor work environment conditions are considered as additional factors affecting health care professionals [16]. Further, there are other elements that cause stress such as long duration of standing required by the service, sleeplessness due to being on night shifts, and eating disorders [17].

Job stress is common among health care providers rather than any other profession, i.e. the increased workload, work environmental factors and work disparities [18]. Radiologist in New Zealand, have experienced reduced levels of stress in the private clinics rather than their counterparts in the public ones [19]. This is beside their exposure to distinctive kinds of stressors which are mainly the intensive contact with patients who undergo pains and death [20]. Studies showed that people suffered from occupational stress have also suffered from poor psychological well-being [21]. Work stress may get increased among female professionals due to the family responsibilities that compel them to respond in an imbalanced manner. Work stress and dissatisfaction of job might be greater among female professionals or sonographers due to the family, social and professional demands [22].

The work environment includes many dimensions having biopsychosocial features of the work setting [23]. These dimensions determine the satisfaction level of workers and their level of stress [24]. The working conditions are representing the central aspects that induce the level of stress [1,23]. For the clinical intervention to get effective outcomes; the personal characteristics of the healthcare providers are significantly related to the positive change that these healthcare providers must leave in promoting the health of their clients. The current study reflects on the outcomes of an investigation that explores the sonographers' work experiences at the work environment and its relations to mental health. Furthermore, various lifestyles have been studied in relation to work context and work stress. After reviewing literature following hypotheses were formulated:

- There will be significant relationship of work context and work stress among sonographers in Riyadh.

- There will be significant relationship between lifestyle, work context and work stress among sonographers in Riyadh.

- There will be significant difference among male and female sonographer on work context and work stress level.

\section{Materials and Methods}

The present study used correlational research design. The research method applied is quantitative in nature in which survey technique using two standardized self-report questionnaires were employed. The study was conducted to investigate the relationship of work context and work stress among sonographers in Riyadh during May 2016-April 2017.

The sample of this study was comprised of $(n=153)$ sonographers of Riyadh. Participants were approached in governmental as well as private sectors. Qualified sonographer appointed at various hospitals were included. Minimum work experience was at least 6 months. The tenure of 6 months was considered to avoid adjustment problem.

A brief rating scale was prepared to measure the lifestyle. It included the factors of perceived health, the frequency of physical activity and average sleep. Work Stress Scale [25], measures the level 
of job satisfaction and opportunity for expression and achievement. It has 20 items. It can be scored as yes or no ( 0 and 1$)$. Every yes reply scored as 1 score. More than 16 has been considered as satisfaction. Meanwhile, less than 10 scores signify stress at the job. Work Context Subscale is derived from Work Design Questionnaire developed by Morgeson and Humphrey in 2006 [26]. It contains 14 items altogether. Work Context Subscale has further 4 domains namely Ergonomics (3 items), Physical Demand (3 items), Work Conditions (5 items), and Equipment Use (3 items). This instrument uses a 5-point Likert scale. Responses range from strongly disagree (score 1) to strongly agree (score 5). The third item of ergonomics domain has reversed scoring. A higher score indicates satisfaction with work setting.

All the ethical considerations were fulfilled before conducting the study. Ethical approval from the Departmental scientific sub-committee and Research Ethical committee of College of Health and Rehabilitation Sciences (application code: Z-F004), Princes Nourah Bint Abdulrahman University was sought. Before approaching participants, a letter explained the purpose of the study was sent to hospital administration for getting permission. Consent forms were provided to the subjects to indicate their willingness to participate in the study and to gather demographic information. Participants were assured about the confidentiality of their information. Then standardized scales were administered to individuals. Data was collected by using both means of individual administration and by online survey forms.

Collected data was analyzed by using SPSS (V. 24). Regression analysis was used to measure the predictive association of work context and work stress among sonographers. Additionally, one sample t-test was calculated to confirm the tendency of scores in the group. Pearson coefficient of correlation was conducted to measure the relationship between lifestyle variables with work context and work stress. Lastly, for comparison purpose among male and female sonographers on the variable of work context and work stress, independent sample t-test was calculated.

\section{Results}

Regression analysis was conducted to measure the predictive association of work context and work stress. Initially, Pearson's Correlation was conducted to measure the relationship of subscales of work context with the sum of scores and with work stress. Results in (Table1) indicated that the subscales of work context are having inter consistency with the total score of the work context. Subscale of ergonomics $(\mathrm{r}=.580, \mathrm{p}<.01)$, physical demand $(\mathrm{r}=.499, \mathrm{p}<.01)$, work conditions $(\mathrm{r}=.781, \mathrm{p}$ $<.01)$ and equipment use $(\mathrm{r}=.689, \mathrm{p}<.01)$ were found strongly correlated with total work context scores. Further job satisfaction (work stress) scores also found highly significant correlation with subscale of work condition $(\mathrm{r}=.261, \mathrm{p}<.01)$ and ergonomics $(\mathrm{r}=.201, \mathrm{p}<.05)$. Results are also approving that there was a significant positive correlation between work context and work stress $(\mathrm{r}=.251, \mathrm{p}<.01)$ among sonographers. Furthermore, regression analysis confirmed the predictive relationship $\mathrm{F}(1,151)=10.193, p<.002, \mathrm{R}^{2}=.063$. of work context on stress level.

Table 1. Regression Analysis of Subscales of work context, total work context score and work stress among sonographers.

\begin{tabular}{lcccccc}
\hline \multicolumn{1}{c}{ Variables } & $\mathbf{( 1 )}$ & $\mathbf{( 2 )}$ & $\mathbf{( 3 )}$ & $\mathbf{( 4 )}$ & $\mathbf{( 5 )}$ & $\mathbf{( 6 )}$ \\
\hline (1) Ergonomics & - & & & & & \\
(2) Physical demand & .140 & - & & & \\
(3) Work conditions & $.296^{* *}$ & .071 & - & & \\
(4) Equipment use & $.243^{* *}$ & $.302^{* *}$ & $.320^{* *}$ & - & \\
(5) Work Context & $.580^{* *}$ & $.499^{* * *}$ & $.781^{* *}$ & $.689^{* *}$ & - & \\
(6) Work Stress & $.201^{* *}$ & .025 & $.261^{* *}$ & .114 & $.251^{* *}$ & - \\
\hline
\end{tabular}

${ }^{* *} \mathrm{p}<.01,{ }^{*} \mathrm{p}<.05$ 
138

\begin{tabular}{llll}
\hline Variable & $\mathbf{R}$ & $\mathbf{R}^{2}$ & $\mathbf{R}^{2}$ Adjusted \\
\hline Work Stress & $.251^{\mathrm{a}}$ & .063 & .057 \\
\hline
\end{tabular}

ANOVA for the Regression Equation, work context on work stress among sonographers

\begin{tabular}{lccccc}
\hline Model & Ss & $d f$ & MS & $F$ & p \\
\hline Regression & 217.424 & 1 & 217.24 & $10.193^{* *}$ & .002 \\
Residual & 3220.786 & 151 & 21.330 & & \\
Total & 3438.209 & 152 & & & \\
\hline \multicolumn{5}{c}{${ }^{* *} \mathrm{p}<0.01$}
\end{tabular}

Beta Coefficients for predictors of Work stress among sonographers

\begin{tabular}{cccccc}
\hline Predictors & B & SE B & $\boldsymbol{\beta}$ & $\boldsymbol{t}$ & $\boldsymbol{p}$ \\
\hline (Constant) & 4.594 & 2.992 & & 1.536 & .127 \\
Work Context & .187 & .059 & .251 & $3.193^{* *}$ & .002 \\
\hline \multicolumn{5}{c}{$\mathrm{p}<0.01$}
\end{tabular}

One sample t-test was conducted to confirm the comparative results for the variables of work context and work stress. Results (table 2) indicated that sonographers of Riyadh scored high on both variables that showed high satisfaction toward their job context $(t=98.02, p<.05)$ and toward their job $(t=36.59, p<.05)$. Moreover, the mean score on work stress is higher than cut off point that confirms the higher job satisfaction level of sonographers in general $(\mathrm{M}=14.07>10)$.

Table 2. Results of One-sample t-test and Descriptive Statistics for Work context and work stress among sonographers in Riyadh.

\begin{tabular}{|c|c|c|c|c|c|c|c|}
\hline Variables & $\mathbf{M}$ & SD & $\mathbf{n}$ & $\begin{array}{c}\text { Comparison } \\
\text { Value }\end{array}$ & $\begin{array}{c}\text { 95\% CI for Mean } \\
\text { Difference }\end{array}$ & $\mathbf{t}$ & df \\
\hline Work Context & 50.65 & 1.391 & 153 & - & 50.647 & $98.02^{*}$ & 152 \\
\hline Work Stress & 14.07 & 2.756 & 153 & 10 & $13.31,14.83$ & $36.59^{*}$ & 152 \\
\hline
\end{tabular}

To measure the relationship of lifestyle variables with work context and job satisfaction, Pearson's product moment correlation was conducted. Results (Table 3) are showing the strong positive relationship between physical activity and satisfaction with work context $(r=.225, p<.01)$. Whereas, job satisfaction was found highly correlated with perception of health $(\mathrm{r}=.214)$ and healthy average sleep $(\mathrm{r}=.242, \mathrm{p}<.01)$.

Table 3. Correlation between lifestyle, work context and work stress.

\begin{tabular}{lccccc}
\hline Variables & Health & Physical activity & Sleep & Work Context & Work Stress \\
\hline Health & - & & & & \\
Physical activity & -.116 & - & & & \\
Sleep & $.250^{* *}$ & -.066 & - & & \\
Work Context & .139 & $.225^{* *}$ & .053 & - & - \\
Work Stress & $.214^{* *}$ & -.109 & $.242^{* *}$ & $.251^{* *}$ & \\
\hline
\end{tabular}

${ }^{* *} \mathrm{p}<.01,{ }^{*} \mathrm{p}<.05$

To permit comparison across domains, results (Table 4) shows that there is no statistically significant difference among male and female sonographers on the variables of work context and 
work stress. Although cutoff score for work stress is 10 but male sonographers ( $M=15.36)$ were found more satisfied with their job as compared to female sonographers (13.72).

Table 4. Gender difference in Work context and work stress among sonographers in Riyadh.

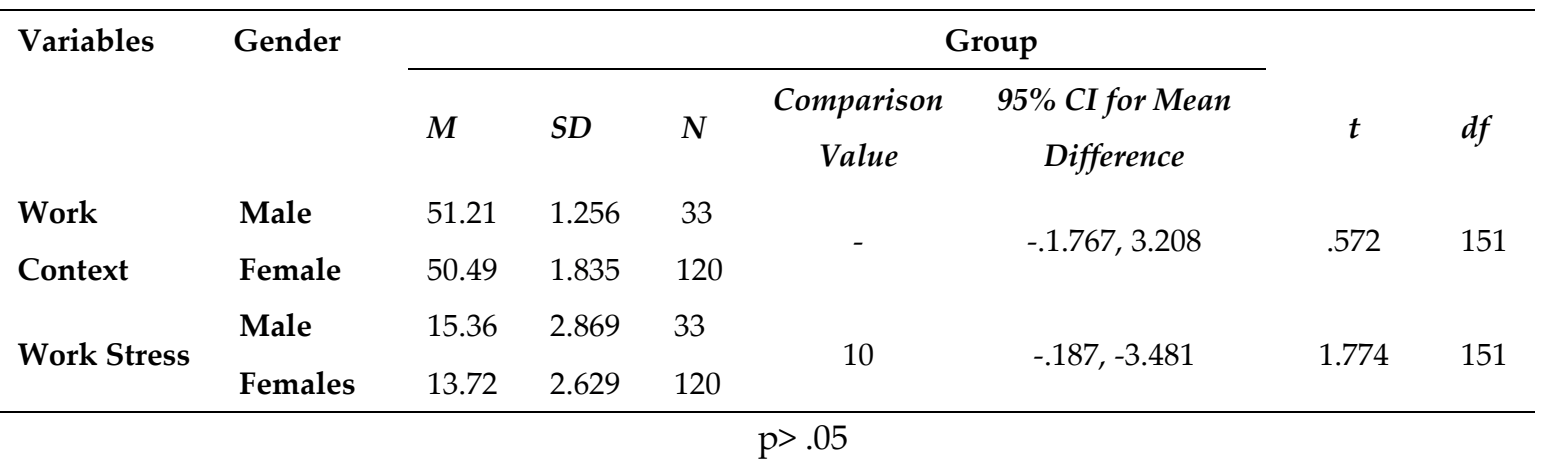

\section{Discussion}

Work design or work context represent the satisfaction and self-motivational aspect of workers [27]. Furthermore, it is related to the efficiency and level of performance. If the person finds working environment or context appropriate to work that will increase the motivation, satisfaction and performance level. Work context including standardized ergonomics, appropriate physical workload, good working conditions, and use of equipment under controlled procedures, can enhance the work efficiency [28]. All the factors in work contexts are equally important. Ergonomics allows the sonographers to complete their tasks in an appropriate manner that can help to maintain their physical health and protect them from work-related injuries. Therefore, the factor of ergonomic is found having (33\%) effect on satisfaction with work context. Second variable of physical demand is explaining the load of work and explaining the variation of $24 \%$. Working condition was found the most influencing factor with the variation of $61 \%$. Fourth variable was equipment use that is related to technology and complexity. This variable was found having the second greatest impact factor (47\%). This has been statistically supported in this current study. All the subscales of work context were highly correlated with total scores. It represents that sonographer in Riyadh were experiencing high quality of working environment under standardized application of procedural protocol. It was found in previous researches that if health professionals were not having good working settings that affects their satisfaction level and performance as well [24, 29]. Additionally, another result is valuable to explain regarding significant relationship of job satisfaction with work conditions and ergonomics. These variables were found contributing to the satisfaction level or alternately decreasing the stress level among sonographers. Predictive association of work context with stress level strengthened the results.

Lifestyle has been found impacting the physical and psychological health of health care professionals [7]. In referring to the sonographers, healthy lifestyle of physical exercise it was found correlated with satisfaction to work context. It is similar to previous studies that addressed the issue of reducing the chances of injuries by providing recommendations to improve the lifestyle of sonographers. Morton and Delf in 2008 [9], have discussed various themes related to musculoskeletal injury among sonographers and suggested that muscle strengthening exercises, stretches and relaxing can help to prevent injuries. Other studies $[12,6]$ also recommended to raise the awareness of sonographers due to high ratio of MSI occurrence, ergonomics, psychological effects on health. Moreover, average sleep and perception of good health was found correlated with job satisfaction. It is consistent with previous studies, where sonographers perceived that their life had been compromised by their work and impact upon their sleep patterns [30].

Although in previous studies it was found that female sonographer were having higher occurrences of MSI thus it was hypothesized to measure the difference of satisfaction with work context and job among male and female sonographers. However, no significant difference was found on both of the variables. It can be explained by having less number of male participant in the study. 
Whereas, difference of mean scores is providing some valuable results. Mean score of male sonographers is high on satisfaction with the working environment as well as on job satisfaction (work stress). On job satisfaction, both groups scored higher mean than the comparison value. It can be explained due to conducting the standardized procedure of protocol approved by Ministry of Health for all sonographer that yields no difference.

There are some limitations of the study. The respondents of this current study were predominantly female sonographers which demands for increasing male sonographers in future similar studies to compare the different responses between males and female sonographers.

A similar study should be extended to other regions in the Kingdom of Saudi Arabia to obtain a broader interpretation of the factors that influence sonographers' psychophysiological wellbeing as well as job satisfaction. Furthermore, the sonographers' job satisfaction and overall organizational contexts mainly the psychological correlates of work context particularly the social and interpersonal interaction among sonographers need to be investigated for specific socio-economic and development purposes. The lifestyle of diet, work/rest cycle, taking care of health and smoking (health-harming behaviours) can be included.

To improve the work context for sonographers, it is recommended to provide hands-on, multidisciplinary training programs to offer essential information for machine users experience through ongoing proven evaluation techniques. It is also recommended for sonographers to demonstrate several bodily exercises for example; stretching techniques to enable them to avoid repetitive strain injuries. It is essential to take frequent breaks at work, to get up and walk or stretch, to break the extended sitting cycle and to reduce the severe effects of sitting. Awareness regarding work/rest cycle to administration and sonographers can increase the satisfaction level towards work.

\section{Conclusions}

It can be said that work context is neither just related to physical comfort (i.e. avoiding fatigue) nor with work efficiency solely. Satisfaction with the working environment can be directly related to psychological factors just like stress. It was found that if sonographers are satisfied with ergonomics, physical demand of work, work conditions and equipment use it may lead toward the satisfaction of work context, increased motivation and productivity. On the other hand, satisfaction with work context can lead toward satisfaction towards job or lesser levels of stress. Some essential life-styles were highlighted in this study. Physical exercise, average sleep and perception of health were correlated with work context and work satisfaction. Specific, considerations should be given to regulate the extreme work assignments and time pressures as it has been proved from the literature that these factors may augment the work stress and increase or worsen the emotional/psychological reactions of sonographers and might lead to stress and MSI. This study has also recommended that healthcare settings must work to create conducive work conditions for its employees that are conducive to employees' satisfaction with autonomy, competence, and affiliation.

Acknowledgments: This research did not receive any specific grant for research work or to cover the cost to publish in open access from funding agencies.

Author Contributions: U.Z and L.F.H conceived and designed the survey; L.F.H gathered all the permission and contacted to hospitals via email; S.S.A and S.M.A.E released and the recruited email and survey; H.D.Q and U.Z analysis and interpreted the data; U.Z and S.S.A have drafted the work and revised it.

Conflicts of Interest: The authors declare no conflict of interest. 


\section{References}

1. Montgomery, A. J.; Panagopolou, E.; Benos, A. Work-home interference as a mediator between job demands and job burnout among doctors. Stress \& Health 2006, 22, 203-212. doi:10.1002/smi.1104.

2. Munn, S. L.; Chaudhuri, S. Work-Life Balance: A Cross-Cultural Review of Dual-Earner Couples in India and the United States. Advances in Developing Human Resources 2016, 18 (1) 54-68. DOI: $10.1177 / 1523422315616342$

3. LaMontagne, AD.; D'Souza, RM.; Keegel, T.; Shann, CB. An integrated approach to workplace mental health: an Australian feasibility study. International Journal of Mental Health Promotion 2014, 16 (4), pp. $205-$ 215. https://doi.org/10.1080/14623730.2014.931070.

4. Stansfeld, S.; Candy, B. Psychosocial work environment and mental health - a meta-analytic review. Scand J Work Environ Health 2006; 32(6):443-462. doi:10.5271/sjweh.1050

5. Pocock, B.; Charlesworth, S.; Chapman, J. Work-family and work-life pressures in Australia: Advancing gender equality in 'good times'? International Journal of Sociology and Social Policy 2013, 33(9/10), 594-612. https://doi.org/10.1108/IJSSP-11-2012-0100

6. Larsen, A. K.; Holtermann, A.; Mortensen, O. S; Punnett, L.; Rod, M. H.; Jørgensen, M. B. Organizing workplace health literacy to reduce musculoskeletal pain and consequences. BMC Nurs 2015. 14: 46. https://doi.org/10.1186/s12912-015-0096-4

7. Enns V.; Currie S.; Wang J. Professional autonomy and work setting as contributing factors to depression and absenteeism in Canadian nurses. Nurs Outlook 2015, 63(3), 269-77. doi: 10.1016/j

8. Gunnarsdottir, S.; Rafferty, A. M. Enhancing working conditions. In: Book Human resources for health in Europe, C. A. Dubois, M. McKee \& E. Nolte (Eds.).; McGraw-Hill Education:. Open University Press, UK, 2006; pp.155-172; ISBN 0335218563.

9. Morton, B; Delf, P. The prevalence and causes of MSI amongst Sonographers. Radiography 2008, 14, 195200. DOI: 10.1016/j.radi.2007.02.00

10. Saini, N.; Agrawal, S; Bhasin, SK.; Bhatia, MS; Sharma, AK. Prevalence of stress among resident doctors working in Medical Colleges of Delhi. Indian J Public Health 2010, 54 (4) 219-23 DOI:10.4103/0019557X.77266.

11. Bovier, P. A.; Perneger, T. V. Predictors of work satisfaction among physicians, Eur J Public Health 2003, 13, 299-305, doi-org.sdl.idm.oclc.org/10.1093/eurpub/13.4.299

12. Feng Q.; Liu S.; Yang L.; Xie M.; Zhang Q. The Prevalence of and Risk Factors Associated with Musculoskeletal Disorders among Sonographers in Central China: A Cross-Sectional Study. PLoS ONE 2016, 11(10): DOI 10.1371/journal.pone.0163903.

13. Evans K.; Roll S.; Baker J. Work-Related Musculoskeletal Disorders (WRMSD) Among Registered Diagnostic Medical Sonographers and Vascular Technologists: A Representative Sample. J DIAGN MED SONOG 2009, 25(6):287-99. DOI: 10.1177/8756479309351748

14. Simonsen, J. G.; Axmon, A.; Nordander, G.; Arvidsson, I. Neck and upper extremity pain in sonographer'sAssociations with occupational factors. APPL ERGON 2017, 58. 245-253. DOI: 10.1016/j.apergo.2016.06.019

15. Arvidsson, I.; Simonsen, J, G.; Dahlqvist, C.; Axmon, A;, Karlson, B.; Björk, J; Nordander, C. Cross-sectional associations between occupational factors and musculoskeletal pain in women teachers, nurses and sonographers. BMC MUSCULOSKELET D 2016, 17:35. DOI 10.1186/s12891-016-0883-4

16. Coffin C. Work-related musculoskeletal disorders in sonographers: a review of causes and types of injury and best practices for reducing injury risk. Reports in Medical Imaging 2014, 15. doi: 10.2147/rmi.s34724. DOI https://doi.org/10.2147/RMI.S34724

17. Karwowski, W.; Jang, RL.; Rodrick, D., Peter, MQ. Self-evaluation of biomechanical task demands work environment and perceived risk of injury, by nurses: a field study. Occupational Ergonomics 2005. 5:13-27. Retrieved from https://content.iospress.com/articles/occupational-ergonomics/oer00096. On November 20, 2017.

18. Pelletier, KR.; Herman P.M.; Metz, R.D. Health and Medical Economics Applied to Integrative Medicine. Explore (NY), 2010, 6, 2, 86-99 https://doi.org/10.1016/j.explore.2009.12.009.

19. Lim, R. C.; Pinto, C. Work Stress, Satisfaction and Burnout in New Zealand Radiologists: Comparison of Public Hospital and Private Practice in New Zealand. J MED IMAG RADIAT ON 2009, 53 (2): 194-9. DOI: 10.1111/j.1754-9485.2009.02063.

20. Girgis A.; Hansen V.; Goldstein D. Are Australian oncology health professionals burning out? A view from the trenches. EUR J CANCER 2009, 45(3): 393-399. DOI: 10.1016/j.ejca.2008.09.029. 
21. Marchand, A; Demers, A; Durand, P. Does work really cause distress? The contribution of occupational structure and work organization to the experience of psychological distress. Soc Sci Med 2005, 61(1):1-14. https://doi.org/10.1016/j.socscimed.2004.11.037.

22. Sumra, M. K.; Schillaci, M. A. Stress and the Multiple-Role Woman: Taking a Closer Look at the “Superwoman." PLOS ONE 2015, 10(3), http://doi.org/10.1371/journal.pone.0120952

23. Chan A.O.M.; Huak C.Y. Influence of work environment on emotional health in a health setting. OCCUP MED-C 2004, 54, 207-212. https://doi-org.sdl.idm.oclc.org/10.1093/occmed/kqh062

24. Ugwu, A C.; Egwu,O. A.; Nwobi, I. C.; Oluware, N. F. Occupational stress among radiographers: the impact of sonography responsibility. Internet Journal of Medical Update, 2009. 4 (1), 3-6. Retrieved from http://www.geocities.com/agnihotrimed. On November 15, 2017.

25. Public Service Management Wales. 'Releasing your potential: A guide to developing a successful career within Welsh Public Services', Public Service Management Wales, 2007. From http://www.gov.ai/documents/publicadmin/Avisory\%20Leaflet\%20Managing\%20Stress\%20in\%20the\%20 Workplace.pdf

26. Morgeson, F. P.; Humphrey, S. E. The Work Design Questionnaire (WDQ): Developing and validating a comprehensive measure for assessing job design and the nature of work. J APPL PSYCHOL, 2006, 91(6):1321-1339. DOI: 10.1037/0021-9010.91.6.1321

27. Christian, M.S.; Garza, A.S.; Slaughter, J. E. Work Engagement: A Quantitative Review and Test of its Relations with Task and Contextual Performance. PERS PSYCHOL, 2011, 64, 1, 1-288. DOI: 10.1111/j.17446570.2010.01203.x

28. Punnett, L.; Cherniack, M.; Henning, R.; Morse, T.; Faghri, P.; Faghri, P.; The CPH-NEW Research Team. A Conceptual Framework for Integrating Workplace Health Promotion and Occupational Ergonomics Programs. Public Health Rep, 2009, 124 (Suppl 1): 16-25. https://doi.org/10.1177/00333549091244S103

29. ILO Encyclopedia of Health and safety. Ergonomics. (1998). (4th ed.). Available on line: http://www.ilocis.org/documents/chpt29e.htm Retrieved on 17 November 2017.

30. Muir, M.; Hrynkow, P.; Chase, R.; Boyce, D.; McLean, D. The Nature, Cause, and Extent of Occupational Musculoskeletal Injuries among Sonographers. J DIAGN MED SONOG 2004, 20 (5):317-25. doi/abs/10.1177/8756479304266737 